\title{
Optimization of E-Commerce Supply Chain Management Process Based on Internet of Things Technology
}

\author{
$\operatorname{Min} \mathbf{W u}$ \\ School of Economics and Management, Chongqing Youth Vocational \& Technical College, Chongqing 400712, China \\ Correspondence should be addressed to Min Wu; 20131052@cqnu.edu.cn
}

Received 2 March 2021; Revised 17 April 2021; Accepted 24 April 2021; Published 4 May 2021

Academic Editor: Zhihan Lv

Copyright ( $\odot 2021 \mathrm{Min}$ Wu. This is an open access article distributed under the Creative Commons Attribution License, which permits unrestricted use, distribution, and reproduction in any medium, provided the original work is properly cited.

\begin{abstract}
The widespread use of Internet technology has changed people's traditional life mode and created a new market transaction mode, namely, e-commerce platform. The Internet of Things can carry out real-time monitoring and management of any product in e-commerce and not only can realize information sharing in commercial activities but also can play a greater role in the protection of personal and enterprise information security. In this context, the efficiency and low cost of information flow, cash flow, logistics, and human resources among enterprises are particularly important. The Internet of Things technology is a means to effectively improve and optimize the operation mode of the supply chain. This paper analyzes the status of traditional supply chain management, which discusses the development of a supply chain management based on the Internet of Things technology. Finally, this paper analyzes how to realize the optimization strategy of e-commerce supply chain management based on the Internet of Things technology, which provides strong support for the informatization of e-commerce supply chain management. Through the application of the Internet of Things technology, small- and medium-sized enterprises can optimize the workflow and circulation links of the e-commerce supply chain management, enhance the matching level of product value and information transmission, improve the supply chain operation mechanism, and increase economic benefits.
\end{abstract}

\section{Introduction}

With the rapid development of the information industry and the popularization of the international Internet, a solid foundation has laid for e-commerce and Internet of Things technology. Thus, the mobile, individual, and virtual characteristics of e-commerce are more prominent. E-commerce platform is the use of Internet technology to network scheduling product resources. For this reason, in addition to relying on information technology to realize the construction of e-commerce platform, it also needs the support of a suitable supply chain network system to adapt to the background of "Internet +" under the development needs of e-commerce platforms. Different from the traditional MRP, MPRII, ERP, and other "procurement-production supply chain" models, China's e-commerce supply chain mainly serves online marketing $[1,2]$. Particularly after 2008, the number of e-commerce companies in China and their revenue scale have grown rapidly. In order to adapt to this change, large e-commerce companies have begun to build an e-commerce supply chain system. The e-commerce supply chain owners represented by Taobao and JD.com have the absolute right to speak in the entire supply chain. At the same time, in order to achieve the optimal management of e-commerce supply chain costs, a hierarchical e-commerce supply chain strategy has gradually formed, and a C-end distribution mechanism with express delivery as the main mode has formed, which has also promoted supply to a certain extent [3]. The market-oriented operation of each node of the chain has made great contributions to improving the quality of logistics. Since then, the overall satisfaction of e-commerce supply chain services under the background of "Internet +" has also improved significantly.

However, after 2018, as the growth rate of Internet users has been slowing down, the cost of new customers of e-commerce companies has increased relatively, and the Internet-centric e-commerce integration of big data technology and Internet of Things technology has broken 
through traditional marketing models. The emergence of the concept of "unbounded retail" has become the basis for the strategic development of e-commerce supply chains in the new era [4]. In this process, the e-commerce supply chain has been upgraded in terms of products and circulation, and the "end-to-end" service of the e-commerce supply chain under the background of "Internet +" has been realized, satisfying consumers' demand for the e-commerce supply chain under the new situation. Based on the extensive application of Internet technology, e-commerce platforms play an increasingly important role in market transactions. The development of e-commerce supply chains under the background of "Internet +" changes the traditional business operation model while also innovating traditional supply chain management was made. With the continuous increase in the number of e-commerce companies, the adaptive contradictions of the e-commerce supply chain in terms of technology and systems have become increasingly apparent. The scientific, integrated, and shared development of e-commerce supply chain management supported by the Internet is particularly important [5]. On the basis of realizing effective control of supply chain logistics costs, building an e-commerce supply chain system in the context of "Internet+" can strengthen the market responsiveness of the supply chain and promote the sustainable and in-depth development of e-commerce supply chain strategy in the context of "Internet+." At present, China is in a stage of comprehensively deepening reforms and transforming the economy to a new normal, which has created good preconditions for accelerating the development of modern logistics industry. The "13th Five-Year Plan" points out the reform and development direction of the logistics industry and requires actively promoting the transformation and upgrading of the traditional logistics industry to build a modern logistics industry $[6,7]$.

At present, global e-commerce and supply chains lose hundreds of billions of dollars a year due to untimely information transmission, information distortion, and information exchange errors. Because the information of the entire supply chain cannot be obtained or is not obtained in time, the actual application demand is amplified layer by layer in the information transmission process of the supply chain, resulting in periodic overproduction and shortage of goods. To improve the data collection methods of enterprises, it is necessary for enterprises to build an intelligent and efficient logistics network to provide support for efficient and accurate decision-making of enterprises. The emerging and vigorous development of modern Internet of Things also provides a new way for the construction of logistics intelligent space. The Internet of Things uses radio frequency identification (RFID), GPS tracking technology, and enterprise application systems combined with various information sensing devices to connect all information with the Internet in real time to achieve intelligent management and identification. Use the Internet of Things technology to obtain item representation information, to achieve the purpose of identifying items and real-time supply chain tracking, and to realize intelligent logistics supply chain management. The application of Internet of Things technology in the management of e-commerce supply chain will make the entire e-commerce supply chain become completely transparent. Enterprises can realize real-time monitoring of each product and manage the logistics system. Companies can monitor and share information on the circulation of products in the supply chain. They can also analyze and predict the information that products will generate at each stage of the supply chain. Through the prediction of product information at each stage, they can estimate the probability of accidents or future trends.

\section{Related Work}

Supply chain has always been an important area of research by domestic and foreign experts and scholars, and it is the focus of many enterprise management optimization and improvement. After years of exploration and development, supply chain research has achieved a series of outstanding results, for example, the investment pressure brought by the vertical integration of enterprises, high market risk, wide range of business, fierce competition, and poor ability to deal with risks. Some scholars try to conduct research from the spirit of supply chain contracts, hoping to improve the overall benefits [8]. Some experts are also targeting research on the influencing factors of the supply chain, focusing on the uncertainty of the operation process and the asymmetry of information to conduct in-depth research on risk management [9]. In response to the pressure on human resources and the environment and the growth in people's environment, the feasibility is analyzed. For the problem of commercial information asymmetry, some scholars have studied the coconstruction and sharing of supply chain information to provide supply chain performance and the application of optimization algorithms and computer-aided decisionmaking in the enterprise supply chain. Scholars have studied issues such as supply chain operation strategy optimization and decision-making improvement [10].

In "2016 RFID Market Overview," ABI research predicted the global Internet of Things consumer market and pointed out that in 2016 RFID will be mainly used in traditional fields, such as access control management, car positioning, electronic billing, electronic certification, and animal identification. The market for applications in weather forecasting, vehicle tracking, mobile payment, and supply chain management has reached 70 billion US dollars. In our country, small- and medium-sized enterprises have become the most active and most important part of the national economy, but their informatization level is seriously out of touch. Compared with the light and flexible foreign smalland medium-sized enterprises in developed countries, the business process is still in a state of disorder. As these companies are in their infancy, their main energy lies in scale development and market development, so they lack supply chain management thinking and planning [11]. RFID technology has been gradually promoted and applied in the field of supply chain management. For example, manufacturers use RFID to paste electronic labels on the production line and the load-bearing pallet or conveyor belt of the stacker to improve the precision of supply chain 
management. Typical applications include 3C electronic product production line, liquor filling management, cigarette production storage, and electrical automation assembly line. In the field of production, marketing, supply, and demand, such as the purchase and sale of pollution-free agricultural products in supermarkets. RFID monitoring is used in the production process of agricultural products, $\mathrm{RF}$ electronic tags are used in the procurement process, and the real-time positioning and tracking system combined with Beidou navigation and RPID is used in the distribution process. These technical means effectively improve the management level of the supply chain. Sharma believes that e-commerce supply chain finance involves more participants and has a more complex and dense network. Once credit data are transmitted in the process of employees, it is contrary to professional ethics [12]. The entire supply chain will present serious imbalances and other issues. Perera et al. believe that the upstream and downstream financing companies of the supply chain served by e-commerce platforms are closely connected, small in scale, and poor in antirisk capabilities [13]. Once the supply chain has market risks due to poor management, its contagious effects will affect the entire supply chain. Most of the above studies start from risk influencing factors, risk diffusion paths, and building a risk evaluation system and rarely reduce the overall risk of e-commerce supply chain finance from process management [14]. This paper combines the Internet of Things technology with the e-commerce supply chain process management to provide a new path to solve the problems of low security and high risk, which is of great significance to the e-commerce supply chain process management.

\section{Analysis of E-Commerce Supply Chain Management}

3.1. Traditional Supply Chain Management and Existing Problems. The concept of supply chain is developed from the concept of Extended Production, which extends and delays the production activities of enterprises. The "economic chain" proposed by Peter Drucker became the earliest source of the supply chain, later developed into a "value chain" from Michael Porter, and finally evolved into the current "supply chain." The supply chain has centered on core enterprises [15]. Through the control of information flow, logistics, and capital flow, from the beginning of raw material procurement to the production of intermediate or final products, the sales system will then sell the products to intermediate customers or end consumers to suppliers, manufacturers, and distributors, retailers, and the final consumer chain into a whole functional network structure model. In general, the supply chain is a functional network structure model (Figure 1).

Supply chain management was proposed by Michael E. Porter in 1985. Supply chain management is an effective combination of suppliers, manufacturers, sellers, and logistics to produce goods. It aims to meet the service level while at the same time. A set of management methods that minimizes the cost of the supply chain, getting the right amount of product to the right place at the right time, and minimizing the total cost of production and distribution. The characteristics of supply chain management can be summarized in three aspects [16]. First, optimize the logistics chain within the enterprise and extend it to external partners. Then, obtain the flexibility of product supply and service provision when demand fluctuates. Finally, improve the transparency of the value chain stage. When a company adopts supply chain management, it ultimately wants to achieve the following three goals: first, improving the maximum satisfaction of customers by improving the flexibility and reliability of delivery; second, using supply chain management to reduce inventory and reduce production and distribution costs to achieve the goal of reducing company costs; third, eliminating error costs and abnormal events, which optimizes the overall process quality of the enterprise.

Traditional supply chain management emphasizes the coordination and cooperation between supply chain node enterprises. The information exchange and sharing between enterprises at each node of the supply chain has become the key to achieving coordination and cooperation. However, under traditional economic conditions, there are many problems in supply chain management. Among them, the main problems of supply chain management in e-commerce enterprises are mainly manifested in two aspects, namely, warehouse explosion and logistics efficiency. If an e-commerce company lacks an integrated supply chain management mechanism, it will directly lead to the consequences of liquidation. How to solve the difficult problems of demand uncertainty, supply uncertainty, production uncertainty, and environmental uncertainty in the supply chain is an urgent problem that needs to be solved to accelerate the development of e-commerce.

\subsection{Analysis of Internet of Things Technology and Application} Framework. The Internet of Things, commonly known as the sensor network, uses advanced electronic information sensing technologies such as RFID to collect, electronically mark all items, then connect them to the Internet in real time, and form the Internet of Things to realize intelligent management and identification. According to the working principle, the Internet of Things can be divided into the following three layers, as shown in Figure 2. The first layer is the perception layer, which uses RFID technology as a representative to identify and label various "things." The second layer is the network layer, which is mainly based on $2 \mathrm{G}$ network, $3 \mathrm{G}$ network, $4 \mathrm{G}$ network, and wireless communication network. It completes the transmission and processing of information such as electronic product code EPC and electronic data EDI. The Internet of Things Management Center and the Internet of Things Information Center are both on this floor. The third layer is the application layer, which is mainly the specific application areas of the Internet of Things technology, including green agriculture, industrial monitoring, urban management, smart home, and smart transportation. 


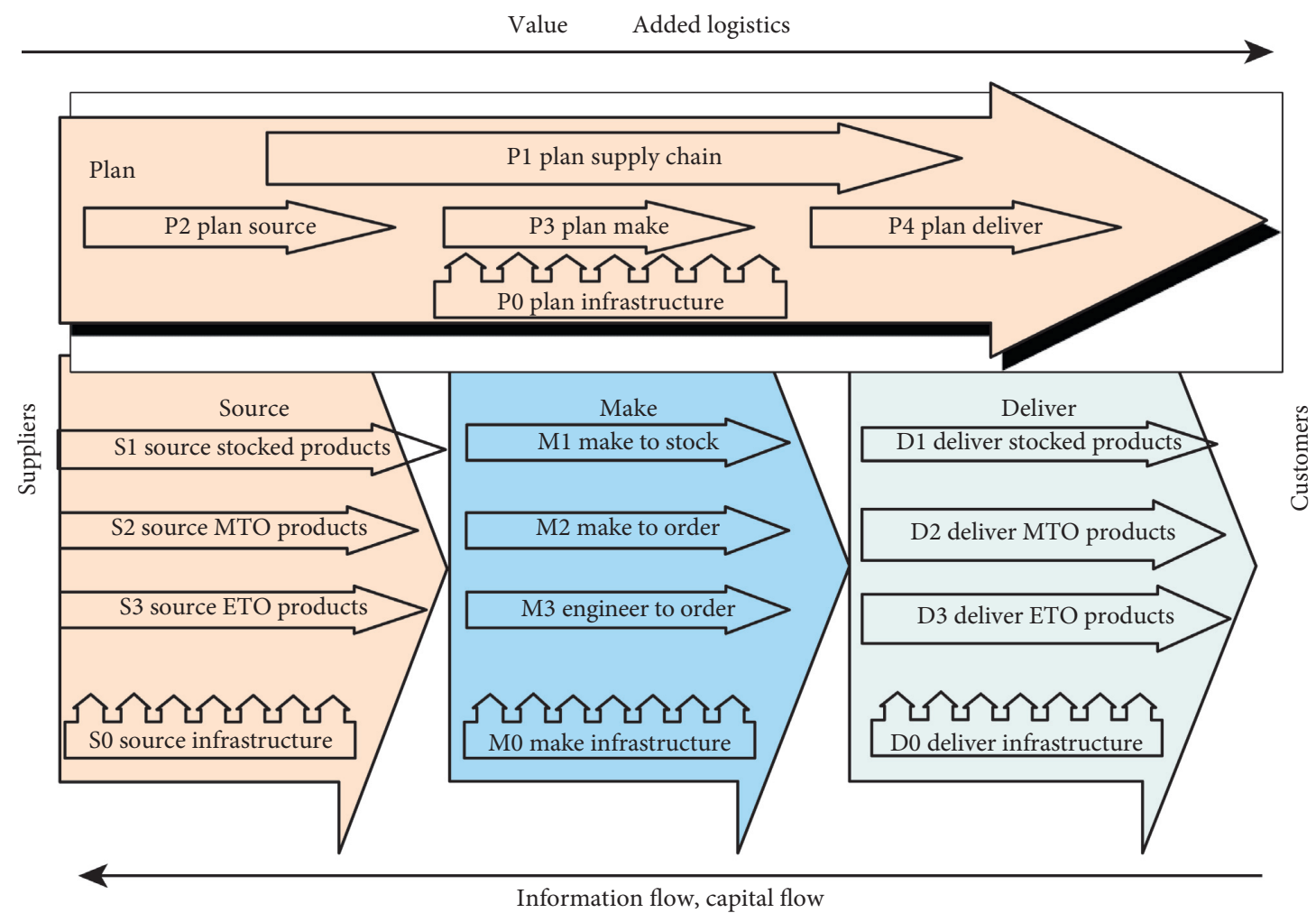

FIGURE 1: Framework of supply chain management.

Some results have been achieved in promoting the informatization of enterprise supply chain management. However, in the face of fierce market competition, how to cultivate, maintain, and develop advantages can only be achieved by applying the latest Internet of Things technology to construct and develop a supply chain management. Intelligent, automated, and visualized management of all links inside and outside the enterprise can reduce the operating costs of the enterprise, improve production efficiency, achieve real-time tracking, monitoring, and management of the supply chain, informationization of supply chain management, and improve the operational efficiency of the entire supply chain.

Supply chain collaboration means that all links of the entire supply chain take the realization of the overall profit maximization of the supply chain as the common goal and are guided by a unified supply chain strategy to coordinate various activities related to the supply chain. Supply chain coordination requires that all links of the supply chain should fully consider the impact of actions taken on the entire supply chain rather than individual links when making decisions. In practice, supply chain coordination is difficult to achieve. The reasons for this result can be summed up, either because the goals of different links in the supply chain are different or even conflict with each other or because the information transmitted between each link is distorted or even distorted. If each link has conflicting goals and they are all committed to maximizing the profit of this link, this will reduce the total profit of the entire supply chain. Therefore, today, the biggest challenge facing the supply chain is to achieve synergy in a supply chain with complex structure, numerous links, and increasing factors of change.

The application of SCMcan enables business exchanges between various Internet of Things technologies and information systems in the supply chain by providing services. Mingyang Biochemical Group's existing information management system, Internet of Things technology system, and supply chain management are encapsulated and released business services in the supply chain management center [17]. These business services are managed and deployed by the management center to form new business processes. For use by managers, through the implementation of the supply chain management architecture, we can use the original system assets to avoid waste and at the same time form a new business process through invocation and encapsulate it into a service interface, thereby greatly improving the interconnection and interoperability between applications and Internet of Things perception technologies. Web Service is a practical supply chain management architecture solution. Devices based on Web Service to provide services can realize device interconnection and functional mutual access. Both the NET platform and the Java platform can realize the interconnection and intercommunication based on the supply chain management architecture. The supply chain management based on the Internet of Things technology is a distributed deployment structure. Through Web Service, it is convenient to apply the Internet of Things technology, integrate various existing system assets, manage and deploy information application systems in various links of the supply chain, and realize resource sharing. 


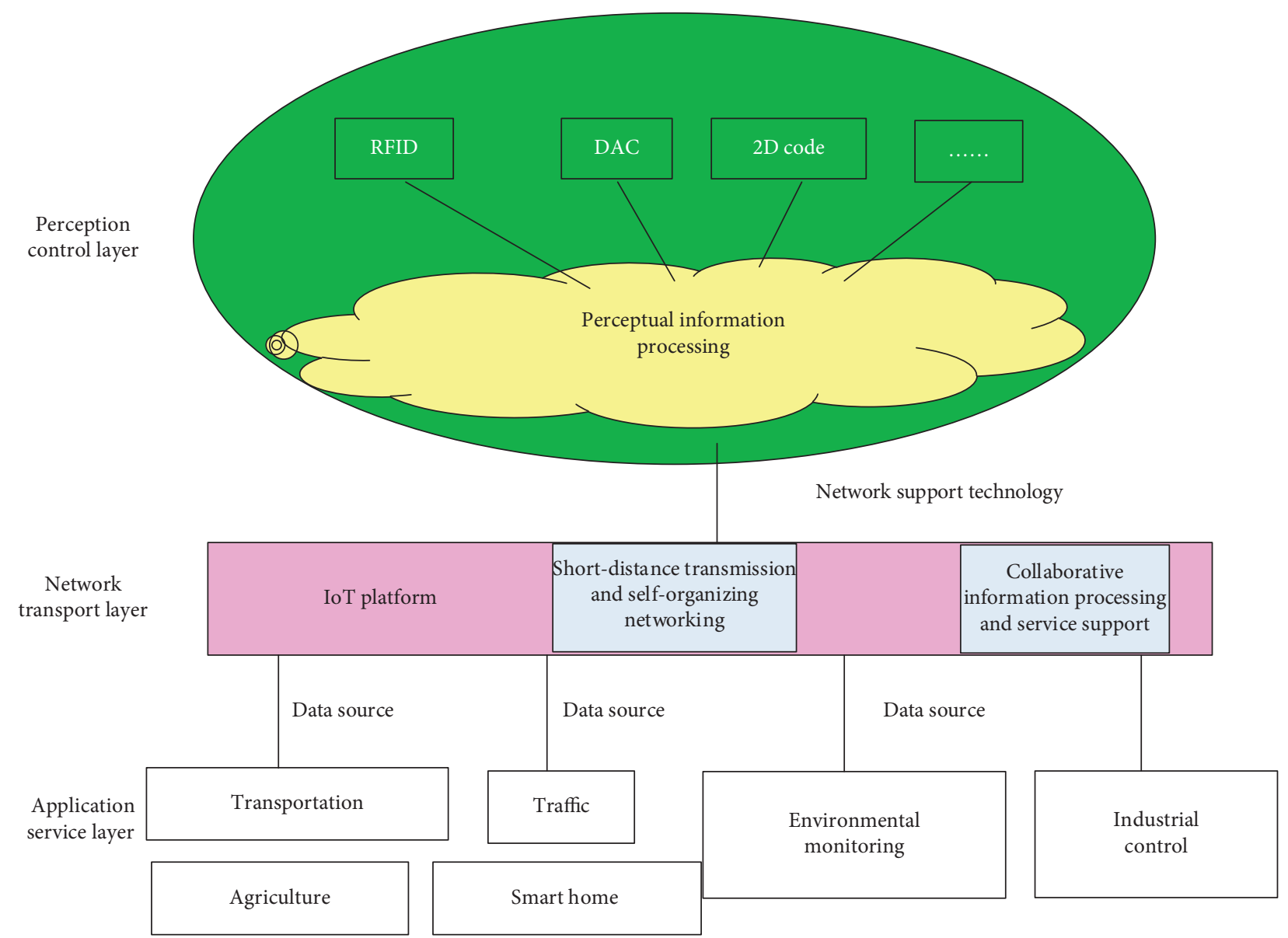

FIgure 2: Classification of the Internet of Things.

\section{Optimization of E-Commerce Supply Chain Management Process under Internet of Things Technology}

\subsection{Function Design of Supply Chain Management Based on} Internet of Things Technology. The Internet of Things serves the entire supply chain by integrating information resources. This is also an important development direction of logistics informatization. It is the focus of the application of the Internet of Things in the logistics industry, which will create a new situation in the development of the logistics industry. The supply chain business process reengineering design combines the Internet of Things technology system with the new logistics business system to transform the operation of each business process. From the logistics cargo information and logistics resource information involved in the business process through perception, we will provide customers and operators with internal and external services to achieve the optimization and integration of logistics business process [18]. The supply chain management adopts the $\mathrm{B} / \mathrm{S}$ architecture, Java.JDK version 1 . Seamless integration improves the operation mode and efficiency of supply chain management. The specific system function design is shown in Figure 3.

The core of supply chain management is integrated and systematic thinking that uses the least cost to obtain the most efficient production efficiency. Under the guidance of this ideology, we integrate suppliers, manufacturers, and wholesale retailers, manage them according to the integrated concept, and effectively integrate resources of related enterprises to achieve efficient operation of the supply chain and improve efficiency. Supply chain management is formed by applying the Internet of Things technology, computer technology, and network technology combined with enterprise management methods.

\subsection{Optimization of Supply Chain Management under E-Commerce Environment}

4.2.1. Supply Chain Model Optimization. Information flow management, capital flow management, and logistics management constitute the three major parts of supply chain management. With the widespread application of e-commerce, information and funds can have transmitted transparently, quickly, and accurately between the member nodes of the supply chain through the Internet, which greatly improves the management of information flow and capital flow in supply chain management. Breaking through and changing the traditional scope of raw material procurement, production, sales, and service is an inevitable requirement of supply chain management in the e-commerce environment. 


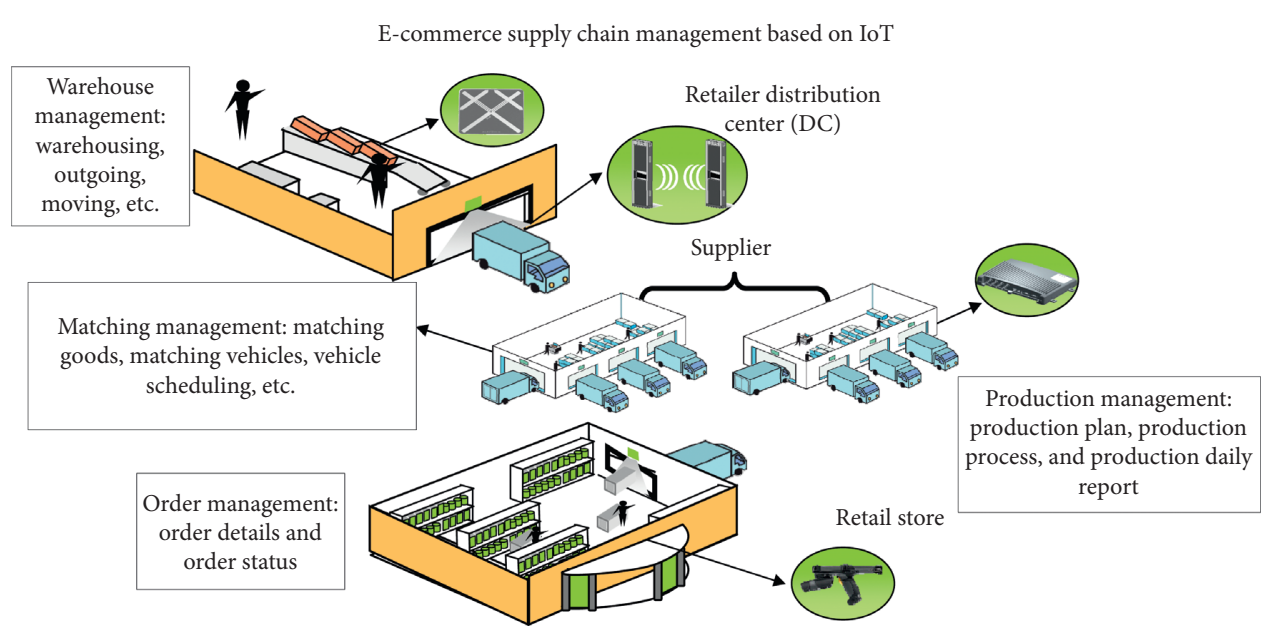

Figure 3: The specific system function design.

Companies in the supply chain are no longer doing their own business and various internal and node companies in the supply chain. Transaction business is regarded as an overall functional process. Through effective and transparent coordination of information flow, capital flow, and logistics in the supply chain, the internal supply chain of the enterprise and the external supply chain of the enterprise have organically integrated and managed to form an integrated supply chain management in Figure 4. In order to adapt to the new requirements of high quality, high flexibility and low cost have been put forward by the market on enterprise production management under the new competitive environment.

The core enterprises of e-commerce and upstream suppliers, downstream end customers, banks, and logistics centers realize rapid information exchange through the Internet, and at the same time, the nodes in the supply chain can also exchange information. Through the application of e-commerce, overthrow the traditional model and effectively connect the islands of various business nodes in the supply chain to achieve true business information integration and sharing. In the transaction link, e-commerce needs to further improve the logistics management link and minimize the time required for logistics in the supply chain, so that the logistics management, information flow, and capital flow management can be unified and synchronized and then a truly powerful and fast-responsive supply chain management.

4.2.2. Optimization of Supply Chain Management in E-Commerce Environment. Warehousing facilities are responsible for the sorting, management, and packaging of commodities and articles, and they are also relatively complicated. Therefore, traditional warehouse management has more or less difficulties. However, when the Internet of Things technology is applied to warehousing technology, a more intelligent warehousing intelligence technology is formed [19]. The warehousing intelligence is in the process of warehousing, you can use the Internet of Things technology to identify items and commodities, and intelligently, the completion of sorting, positioning, measurement, and other tasks can greatly improve the speed of logistics and the quality of work. The optimization of supply chain management under the e-commerce environment is as follows: (1) Adopt third-party logistics (3PL) to actively improve the external logistics of the company. The so-called third-party logistics refers to the logistics operation mode in which the enterprise signs a contract to complete all or part of the logistics service with a third party (generally a professional logistics enterprise) other than the supply and demand side [20]. Third-party logistics is an inevitable result of the development of e-commerce, adapting to the trend of logistics integration, and it is also the development trend of the world's logistics industry today.

$$
\begin{aligned}
& \min : z=\sum_{i j} c_{i j} x_{i j}+\sum_{i} f_{i} y_{i}, \\
& \sum_{i} x_{i j}=1, \forall j, \\
& \text { s.t., } 0 \leq x_{i j} \leq y_{i}, \forall i, j, \\
& y_{i} \in\{0,1\} .
\end{aligned}
$$

$x_{i j}$ is the proportion of $i$ facilities that meet the total demand of the $j$ market; $y_{i}$ denotes whether to use the decision variable of facility $i ; c_{i j}$ is the production and transportation costs required by the $i$ facility to meet all the needs of the $j$ market; $f_{i}$ is the fixed fee for using $i$ facilities.

In e-commerce logistics, distribution technology has always been an important work link for capacity expansion, and it is also the link that is most prone to errors and problems. Logistics distribution often encounters delays in delivery time, wrong delivery locations, and difficulty in tracking delivery information. These problems are the traditional logistics and distribution industry is more serious. The development and optimization of e-commerce logistics can already use the Internet of Things technology. The application of the Internet of Things technology in the distribution link is mainly by adding EPC tags, which are electronic product codes. By adding a unique EPC code to the delivered goods, users and managers can query the 


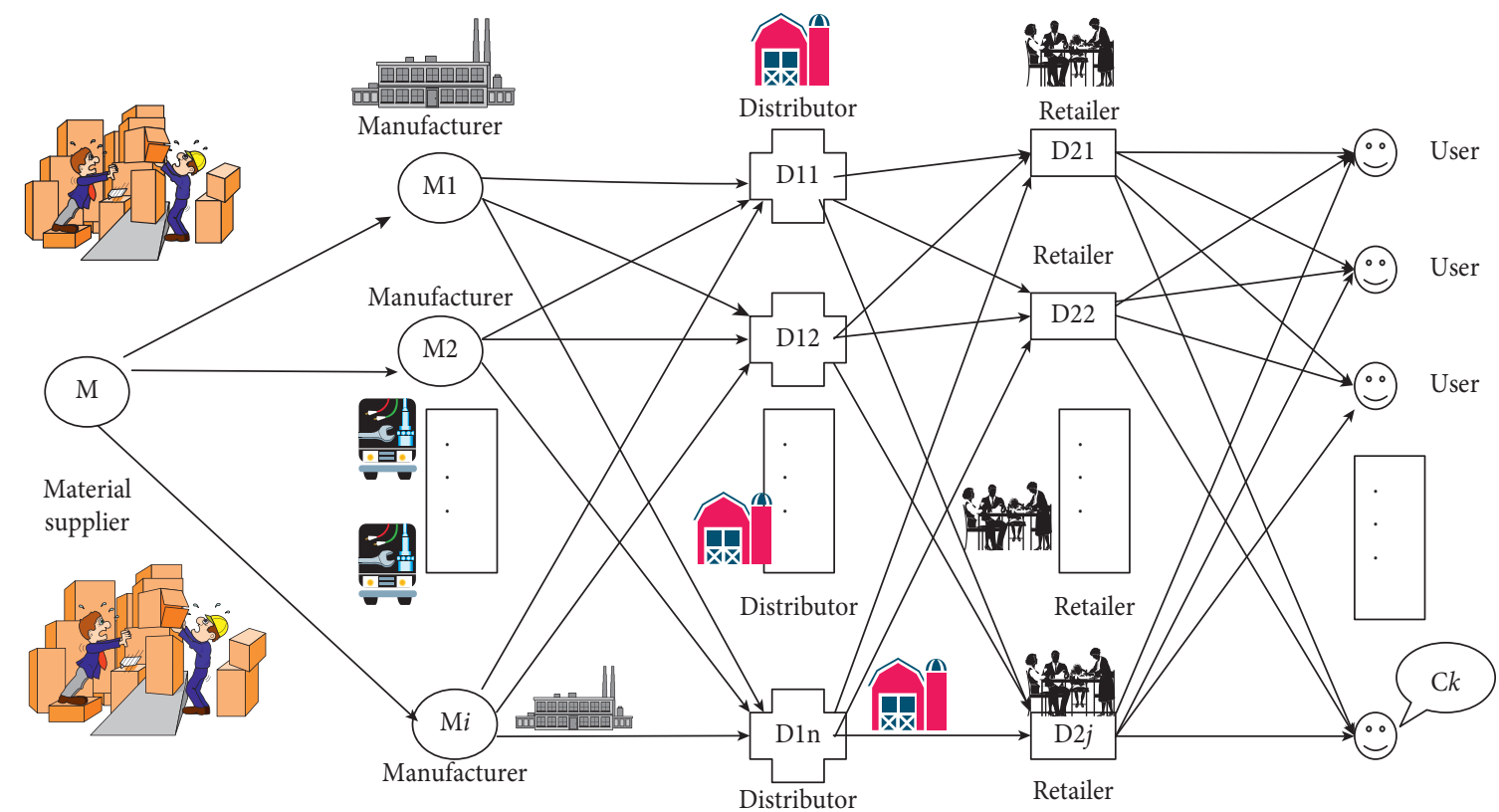

FIGURE 4: Framework of supply chain model optimization.

delivery information in real time according to the code and realize the whole process monitoring and management of the logistics distribution link and product information, which can greatly improve the quality of logistics delivery. (2) Establish and improve the corporate network infrastructure and reform the internal supply chain management model of the enterprise.

$$
\begin{aligned}
& \min : z=\sum_{\text {it }}\left(f_{i t} x_{i t}+\sum_{k} g_{i k t} w_{i k t}+h_{i t} z_{i t}\right), \\
& \text { s.t., } \quad z_{i t}-z_{i t}-1-x_{i t}-\sum k\left(w_{k i t}-w_{i k t}\right)=d_{i t}, \forall i, t, \\
& x_{i t}, z_{i t}, w_{i t} \geq 0 .
\end{aligned}
$$

$x_{i t}$ denotes expanding the capacity of $i$ facilities in period $t$; $z_{i t}$ is the remaining capacity of facility $i$ at the end of $t$; $w_{i k t}$ is the ability to transform facility $i$ into facility $k$ in period $t ; f_{i t}$ is the expenses for expanding the capacity of facility $i$ in period $t ; g_{i k t}$ is the unit cost for converting facility $i$ capacity to facility $k$ capacity in period $t ; h_{i t}$ is the unit cost of maintaining the remaining capacity of facility $i$ in period $t$.

The supply chain management mode in the e-commerce environment is shown in Figure 5.

The realization of supply chain management and e-commerce is based on complete network facilities. Therefore, the organic integration of the intranet and the Internet of the node enterprises in the supply chain can ensure the smooth flow of information and funds in the supply chain management and ensure the efficient operation of the supply chain.

The core enterprises in the supply chain play a key role in strategy formulation and implementation, and the performance evaluation of strategy implementation helps to further examine and adjust the specific strategic measures of supply chain management. Here, a strategy is a unified, comprehensive, and overall plan and action taken by an enterprise to achieve a specific goal to clarify the key measures and related tactical arrangements for the enterprise to achieve future success. Therefore, this paper believes that the long-term strategic goal of the supply chain is to build an Internet-based e-commerce supply chain. The integration of supply chain management applications, in turn, drives the overall e-commerce capability of the supply chain and improves the financial performance of core enterprises and supply chain partners. The strategic development direction of the supply chain is established. The company needs to further explain and communicate internally to establish specific supply chain management strategic objectives and implementation content so that the strategic objectives can be decomposed into the various processes and functional areas of the supply chain to supervise the supply. The final link of strategic management is performance measurement and management of the implementation effect, and the evaluation result is important feedback information for the company to revise and update the strategy in the next step.

4.3. Analysis of Results. E-commerce has brought changes to the entire supply chain management of enterprises, enabling enterprises to shorten the order cycle, reduce overall costs, improve the efficiency of information transmission, and improve the level of corporate decision-making [21, 22]. At the same time, three aspects of quality, cost, and response speed have been effectively improved, which has strengthened the competitiveness of the company. Supply chain management under the e-commerce environment incorporates new ideas and technologies of modern management. It is not only an integrated management idea and method but also an agile, integrated, and systematic advanced 


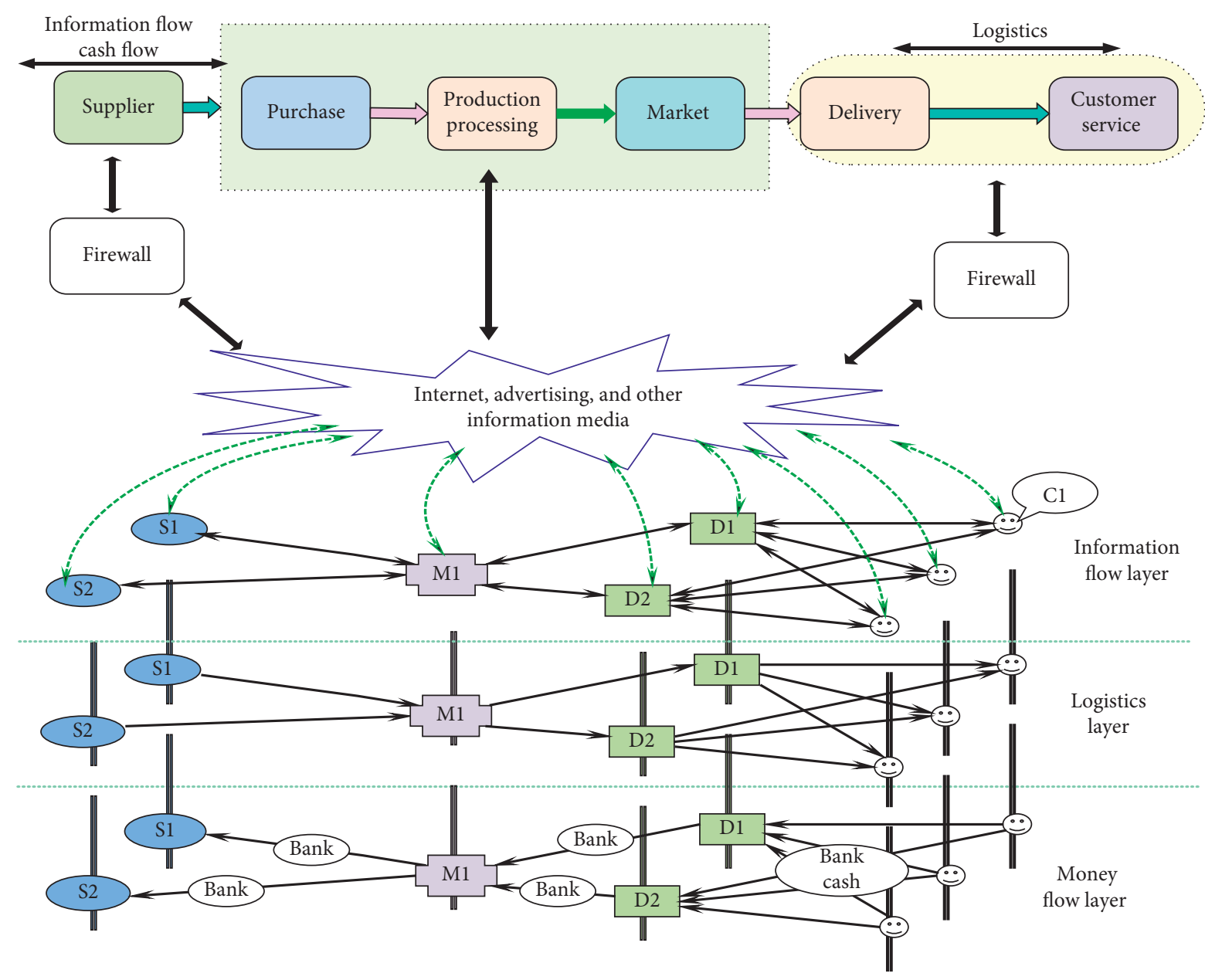

FIGURE 5: Supply chain management optimization in e-commerce environment.

management model. The e-commerce supply chain is to optimize the supply chain as a whole, not just to solve the problems in the supply chain $[23,24]$.

The goal of optimizing supply chain management is to establish an integrated supply chain management. By further optimizing and perfecting the functions of the supply chain management, each link and function of the supply chain can be configured to maximize the overall benefits of the supply chain. This paper takes a company as an example. The experiment includes two raw materials, two components, two products, two suppliers, two component manufacturers, two assembly plants, two distribution centers, two markets, two modes of transportation, two technologies for components and assembly plants, and four time periods. This paper uses GAMS software to construct a supply chain optimization. Without changing the description of the model, users can use different optimization software to solve the defined problems without any modification to the model. The GAMS model description makes full use of the conciseness of mathematical expressions. Similar to the principle of separation of model and data, the model description does not need to change when the data are changed.

This paper uses Excel model to construct a supply chain simulation to simulate the manual decision-making process, and the simulation results can be viewed directly through the Excel table. By comparing with the results of the GAMS model, the correctness and validity of the model are tested in Figure 6.

This case strengthens the construction of informatization, makes full use of modern Internet information technology, and establishes an integrated and unified supply chain management. Use process optimization to realize the system-wide docking and unify all subsidiaries and business departments into one system to ensure that the subsidiaries and business departments can share this information and resources through the process optimization system. Effectively integrate all nodes of the supply chain, and form an integrated supply chain management by coordinating the capital flow, information flow, and logistics of the supply chain. In addition, according to the actual situation of various subsidiaries and business units, the procurement resources are integrated, and the procurement management mode of centralized procurement and decentralized management is implemented. Adjust the organizational structure of the procurement center, and incorporate the procurement functions dispersed in various subsidiaries and business units into the procurement center for unified procurement and unified management. At the same time, the internal 


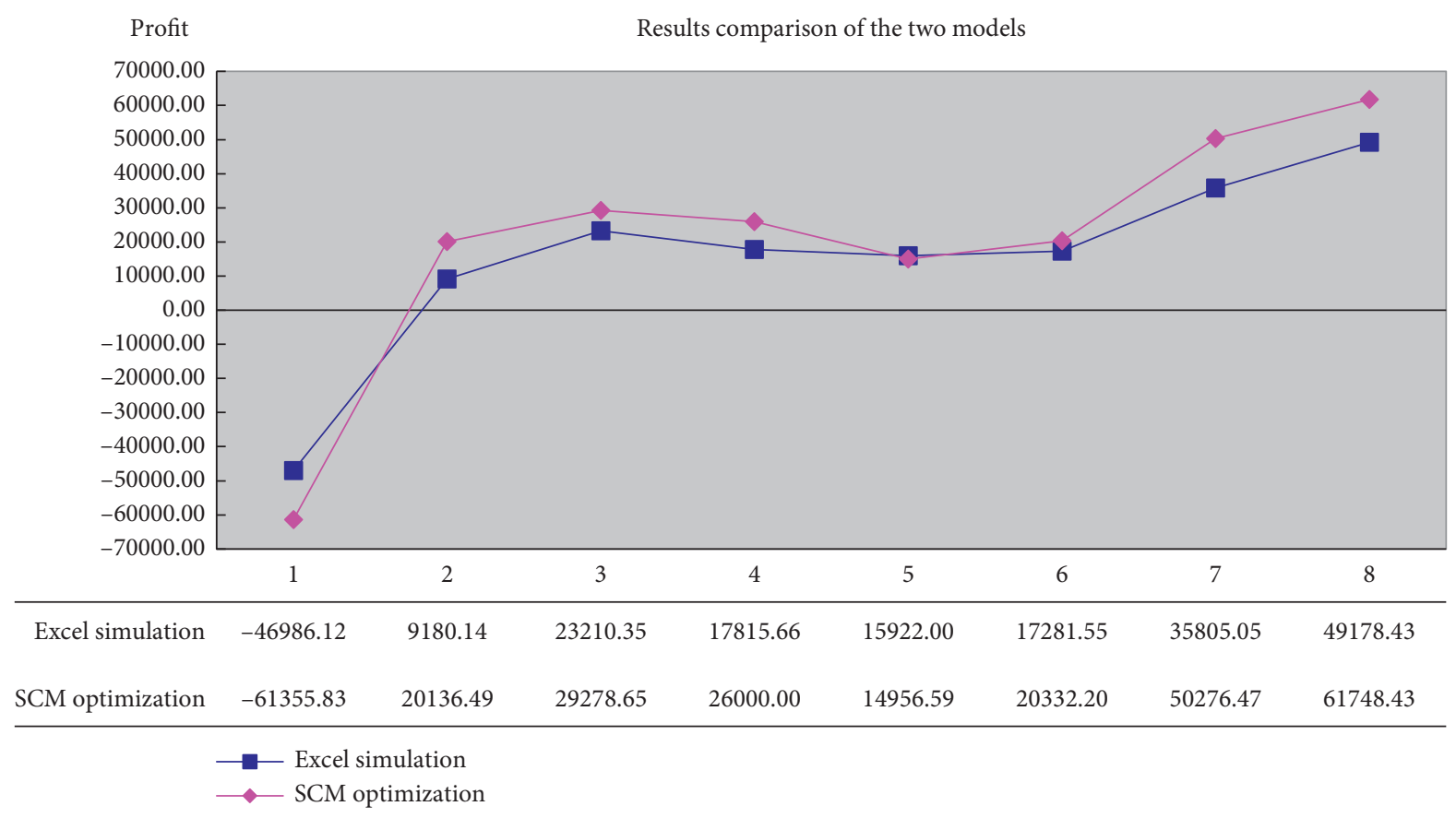

FIGURE 6: The results of the GAMS model.

procurement process should be sorted out to ensure that the process is simple, fast, and effective. This not only allows unified supervision and management of the entire procurement process but also improves work efficiency and effectively reduces procurement costs.

4.4. System Test. During system development, standardizing the development process can effectively guarantee the quality of system development, but before the system has been put into use, software testing is the most important link. Through software testing, we can verify whether the functional requirements and performance of the design document are achieved. It is required to be able to identify weaknesses or errors early, solve problems early, and provide software accuracy, integrity, and quality, thus improving software quality. Software testing generally uses manual random testing combined with automatic means to test the process of software, test whether the requirements are met, know the difference between actual and expected, and help improve software quality. Common testing includes unit testing, integration testing, system testing, and confirmation testing. The testing work runs through the entire process of software development.

The system test of supply chain management based on the Internet of Things technology is divided into the following four stages according to the development progress: white box testing, black box testing, functional testing, and internal public are testing. In addition to discovering problems, we also regularly share experience with participating testers, listen to their improvement suggestions, correct errors, improve interactive physical examination, and further modify and improve the system to achieve the expected goals. A large number of terminals run test scripts concurrently, ignoring server-thinking time, server monitoring response time, click rate, CPU usage, memory operation, and stability testing, and the system running time is 30 minutes. The scene of opening the supply chain server is recorded, test points are recorded in action, and the user's actions to close the web page are recorded in end. In addition, we insert some other transactions for each test point as needed and insert them before the transaction. At the assembly point, according to the test case, the throughput rate is shown in Figure 7.

Complete the stress test of the supply chain management through key indicators such as the number of concurrencies, response time, and resource utilization to determine whether the goal of safety and stability is reached. During execution, the system uses all employees of the virtual group to operate business functions at the same time. The system response time is 1.68 and the occupancy rate of system memory is $49.2 \%$ when all employees of the group access the operation at the same time. The utilization rate of CPU is $18.7 \%$. Based on data analysis, the developed supply chain management meets the requirements of actual operation and the project goal.

\subsection{Strategies to Strengthen Supply Chain Management under} the E-Commerce Environment. Supply chain management mode information flow management, capital flow management, and logistics management in the e-commerce environment constitute the three major parts of supply chain management. With the widespread application of e-commerce, information and funds can be transmitted transparently, quickly, and accurately between the member nodes of the supply chain through the Internet, which greatly improves the management of information flow and capital 


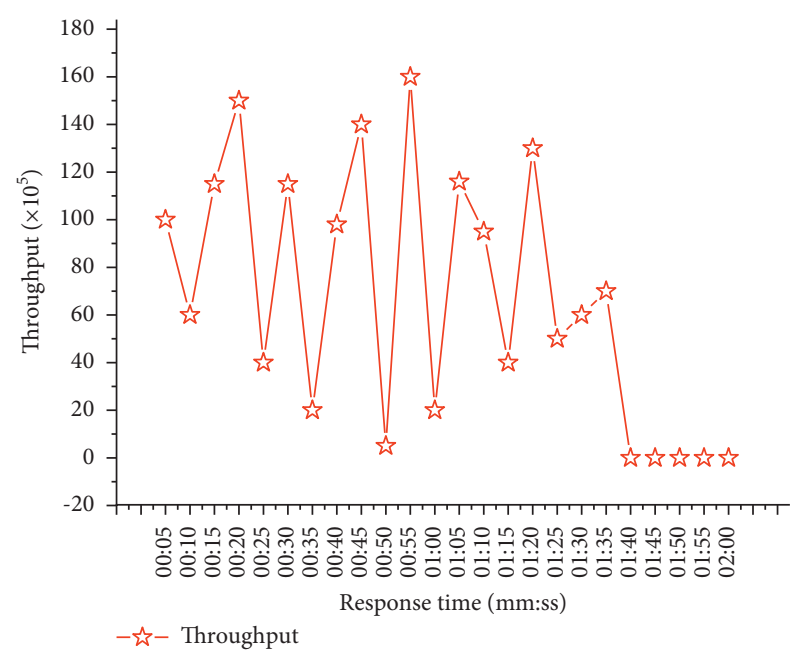

FIgURE 7: Test results of the throughput rate.

flow in supply chain management. Breaking through and changing the traditional scope of raw material procurement, production, sales, and service is an inevitable requirement of supply chain management in the e-commerce environment. Companies in the supply chain are no longer doing their own business, and various internal and node companies in the supply chain are regarded as an overall functional process. Through effective and transparent coordination of information flow, capital flow, and logistics in the supply chain, the internal supply chain of the enterprise and the external supply chain of the enterprise have organically integrated and managed to form an integrated supply chain management in order to adapt to the new requirements of the market for high quality, high flexibility, and low cost of enterprise production management under the new competitive environment. Because the core enterprises of e-commerce and upstream suppliers, downstream end customers, banks, and logistics centers realize rapid information exchange through the Internet, at the same time, the nodes in the supply chain can also exchange information. Through the application of e-commerce, overthrow the traditional model and effectively connect the islands of various business nodes in the supply chain to achieve true business information integration and sharing. In the transaction link, e-commerce needs to further improve the logistics management link and minimize the time required for logistics in the supply chain, so that the logistics management, information flow, and capital flow management can be unified and synchronized and then a truly powerful and fast-responsive supply chain management. Therefore, in order to strengthen supply chain management in an e-commerce environment, arrangements must be made in accordance with the following strategies:

(1) Adopt third-party logistics (3PL) to improve the external logistics of the company. The so-called third-party logistics refers to the logistics operation mode in which the enterprise signs a contract to complete all or part of the logistics service with a third party (generally a professional logistics enterprise) other than the supply and demand side. Third-party logistics is an inevitable result of the development of e-commerce, adapting to the trend of logistics integration, and it is the development trend of the world's logistics industry today.

(2) Establish and improve the enterprise network infrastructure, and reform the internal supply chain management of the enterprise. The realization of supply chain management and e-commerce is based on complete network facilities. Therefore, the organic integration of the intranet and the Internet of the node enterprises in the supply chain can ensure the smooth flow of information and funds in the supply chain management and ensure the efficient operation of the supply chain.

(3) Carry out business process reengineering (BPR) and implement ERP system. Business process reengineering is to fundamentally think and rebuild the business process of an enterprise. Through process reengineering, it focuses on improving the production cost, product quality, product service, and logistics speed of the enterprise, to make the enterprise adapt to the modern customer-centric business environment to the greatest extent.

(4) Strengthen coordination and integration. The competition in the e-commerce environment is the competition between the supply chains, not the competition of enterprises fighting on their own. In order to survive in the e-commerce environment and to improve the competitive advantage of enterprises, enterprises must strengthen the awareness of mutual information sharing within the scope of the supply chain. Enterprises at all nodes in the supply chain share resources with each other, reduce misinformation, reduce unnecessary waste, and ultimately improve operating efficiency.

(5) Pay attention to the construction of Customer Relationship Management (CRM). CRM is an extension of e-commerce supply chain management. CRM breaks through the geographical and organizational restrictions between the supply chain node companies, integrates end customers, suppliers, distributors, and distributors, and truly solves the problems of upstream and downstream management in the supply chain. Feedback from each node is reflected in the supply chain.

\section{Conclusion}

Commercial competition has gradually shifted from competition between companies to competition between supply chains and supply chains. The level and efficiency of supply chain management have become one of the decisive factors for commercial success. At present, global e-commerce loses hundreds of billions of dollars a year due to untimely information transmission, information distortion, and information exchange errors. To improve the data collection methods of enterprises, it is necessary for enterprises to build 
an intelligent and efficient logistics network to provide support for efficient and accurate decision-making of enterprises. The data center, as the main feature of intelligence in the Internet of Things era, makes enterprises who are only accustomed to the traditional logistics management mode confused. At present, the Internet of Things technology is still at the theoretical stage. With the continuous development of the Internet of Things and RFID technology and the deepening of theoretical research, the Internet of Things will change the operation mode of e-commerce supply chain management and realize the intelligent and visualized supply chain management. The Internet of Things technology connects all information with the Internet in real time to realize intelligent management and identification. Supply chain management is an unavoidable strategic means for any enterprise to survive and develop. This paper analyzes the problems encountered in traditional supply chain management and proposes how to optimize the e-commerce supply chain management process under the Internet of Things technology and combine the actual supply chain management of e-commerce enterprises in society. With the support of the Internet of Things technology, the operation of the entire supply chain is clearly visible, and various departments of the supply chain can share information and data and realize the scientific management of the enterprise and accurate forecasting. The construction of an e-commerce supply chain management based on the Internet of Things technology frees enterprises from tedious transactional work and enables them to focus more on supply chain process optimization and collaboration among supply chain members, thereby improving the efficiency of the entire supply chain and flexibility. Due to the adoption of the Internet of Things technology, manual intervention is reduced, efficiency is improved, error rate is reduced, and cost is reduced. Moreover, relevant personnel can actively obtain information and receive push information in real time, so that enterprises in the sublinks of the supply chain can quickly respond to market demand, improve service levels, and enhance corporate competitiveness.

\section{Data Availability}

The data used to support the findings of this study are available from the corresponding author upon request.

\section{Conflicts of Interest}

The authors declare that they have no known conflicts of interest or personal relationships that could have appeared to influence the work reported in this paper.

\section{Acknowledgments}

This research has been financed by the Science and Technology Research Program of the Chongqing Municipal Education Commission: Research on E-Commerce Innovation of Edible Fungi in County Era in "E-Commerce Poverty Alleviation" (Grant no. KJQN201904104).

\section{References}

[1] M. Liu, J. Ma, L. Lin, M. Ge, Q. Wang, and C. Liu, "Intelligent assembly system for mechanical products and key technology based on internet of things," Journal of Intelligent Manufacturing, vol. 28, no. 2, pp. 271-299, 2017.

[2] S. Xu, J. Chen, M. Wu, and C. Zhao, "E-commerce supply chain process optimization based on whole-process sharing of internet of things identification technology," Computer Modeling in Engineering \& Sciences, vol. 126, no. 2, pp. 843-854, 2021.

[3] M. Papert, P. Rimpler, and A. Pflaum, "Enhancing supply chain visibility in a pharmaceutical supply chain," International Journal of Physical Distribution \& Logistics Management, vol. 46, no. 9, pp. 859-884, 2016.

[4] S. Li, "Structure optimization of e-commerce platform based on artificial intelligence and blockchain technology," Wireless Communications and Mobile Computing, vol. 2020, no. 12, 8 pages, 2020.

[5] R. Wang, C. Yu, and J. Wang, "Construction of supply chain financial risk management mode based on internet of things," IEEE Access, vol. 7, no. 99, pp. 110323-110332, 2019.

[6] Y. P. Tsang, K. L. Choy, C. H. Wu et al., "An internet of things (IoT)-based risk monitoring system for managing cold supply chain risks," Industrial Management \& Data Systems, vol. 118, no. 7, pp. 1432-1462, 2018.

[7] Q. Song, Y. Chen, Y. Zhong, K. Lan, S. Fong, and R. Tang, "A supply-chain system framework based on internet of things using blockchain technology," ACM Transactions on Internet Technology, vol. 21, no. 1, pp. 1-24, 2021.

[8] Y. N. Huddar, P. P. Kumatagi, and M. R. Latte, "Digital supply chain management-a review," IARJSET, vol. 4, no. 1, pp. 34-37, 2017.

[9] Z. Tian, Z. Zhang, and R. Gao, "Optimization in e-commerce market network based on value order parameter," Information Technology and Management, vol. 17, no. 2, pp. 187-197, 2016.

[10] A. A. Maroli, V. S. Narwane, R. D. Raut, and B. E. Narkhede, "Framework for the implementation of an internet of things (IoT)-based water distribution and management system," Clean Technologies and Environmental Policy, vol. 23, no. 1, pp. 271-283, 2021.

[11] K. Liu, "Research on the food safety supply chain traceability management system base on the internet of things," International Journal of Hybrid Information Technology, vol. 8, no. 6, pp. 25-34, 2015.

[12] A. Sharma, J. Kaur, and I. Singh, "Internet of things (IoT) in pharmaceutical manufacturing, warehousing, and supply chain management," SN Computer Science, vol. 1, no. 4, pp. 1-10, 2020.

[13] C. Perera, A. Bouguettaya, S. Kanhere, and C. H. Liu, "Guest editorial: introduction to the special section on sensor data computing as a service in internet of things," IEEE Transactions on Emerging Topics in Computing, vol. 7, no. 2, pp. 311-313, 2019.

[14] I. Lee and K. Lee, "The internet of things (IoT): applications, investments, and challenges for enterprises," Business Horizons, vol. 58, no. 4, pp. 431-440, 2015.

[15] J. Park, G. Hwang, and A. J. Dweekat, "A supply chain performance measurement approach using the internet of things toward more practical SCPMS," Industrial Management \& Data Systems, vol. 117, no. 2, pp. 267-286, 2017.

[16] H. B. Trong and U. B. T. Kim, "Application of information and technology in supply chain management: case study of 
artificial intelligence-a mini review," European Journal of Engineering Research and Science, vol. 5, no. 12, pp. 19-23, 2020.

[17] Z. Yu and Y. Chen, "Research on the optimization of aftersales parts supply chain management based on supplier management-taking SAIC general motors after-sales parts as an example," OALib, vol. 5, no. 11, pp. 1-23, 2018.

[18] L.-J. Zhao, B.-H. Xia, L.-M. Lin, S.-H. Xiong, J. Tang, and D.-F. Liao, "Optimization of ultrasound-assisted enzymatic polysaccharide extraction from turpiniae folium based on response surface methodology," Digital Chinese Medicine, vol. 1, no. 3, pp. 239-246, 2018.

[19] F. Zhang, D.-S. Xu, F. You, X.-Y. Qu, and Y.-H. Zhang, "New aspects of poultry feed supply chain," Journal of Computational and Theoretical Nanoscience, vol. 12, no. 12, pp. 6100-6106, 2015.

[20] B. Yan, C. Yan, C. Ke, and X. Tan, "Information sharing in supply chain of agricultural products based on the internet of things," Industrial Management \& Data Systems, vol. 116, no. 7, pp. 1397-1416, 2016.

[21] J. Dobroszek, "Supply chain and logistics controller-two promising professions for supporting transparency in supply chain management," Supply Chain Management: An International Journal, vol. 25, no. 5, pp. 505-519, 2020.

[22] J. Yang, J. Zhang, and H. Wang, "Urban traffic control in software defined internet of things via a multi-agent deep reinforcement learning approach," IEEE Transactions on Intelligent Transportation Systems, 2020.

[23] L. Zhu, "Optimization and simulation for e-commerce supply chain in the internet of things environment," Complexity, vol. 2020, Article ID 8821128, , 2020.

[24] A. Arasteh, "Supply chain management under uncertainty with the combination of fuzzy multi-objective planning and real options approaches," Soft Computing, vol. 24, no. 7, pp. $5177-5198,2020$. 